\title{
СЕМАНТИКА ГОРОДСКИХ И СЕЛЬСКИХ ПЕЙЗАЖЕЙ ЛИТВЫ В ДЕТСКОМ СОВЕТСКОМ КИНЕМАТОГРАФЕ
}

\author{
А. К. Бернатоните \\ Томский государственный педагогический университет, Россия \\ ada_bernaton@inbox.ru \\ С. С. Аванесов \\ Новгородский государственный университет имени Ярослава Мудрого, \\ Россия \\ iskiteam@yandex.ru
}

\begin{abstract}
В статье проанализированы специфические причины появления в советских детских фильмах эпизодов, демонстрирующих городские и сельские ландшафты Дитвы и создающих особую атмосферу в кадре. Поскольку вильнюсское барокко испытало на себе вдияние итальянской архитектуры, то съёмки в Аитве создавали в советском кинематографе илдюзию Италии. Ещё одна из причин дежит в пдоскости инаковости культуры, внутри которой легко сотворить образ врага. Но вместе с этой крайностью в контексте детского кинематографа лежит и полярно другая целевая причина: визуально продемонстрировать абсолютную идентичность дитовского городского пространства российскому, точнее, советскому пространству. Использование ландшафтов дитовских городов носидо мозаичный характер. Определённые места, которые зритель видит в кадре, по смыслу выполняют иную функцию, нежели та, которая характерна для них в реальности. Городское пространство Аитвы в детском советском кинематографе лишено присущей ему семантики. В статье выявияются закономерности, согласно которым авторы фильмов намеренно отказывают в узнаваемости историческим и повседневным объектам этой прибалтийской республики.
\end{abstract}

Кдючевые слова: дандшафтный контраст, Аитва, городская среда, детский советский фильм, визуальный код. 


\title{
THE SEMANTICS OF LITHUANIAN URBAN AND RURAL LANDSCAPES IN SOVIET CHILDREN'S CINEMA
}

\author{
Ada Bernatonite \\ Tomsk State Pedagogical University, Russia \\ ada_bernaton@inbox.ru \\ Sergey Avanesov \\ Yaroslav-the-Wise Novgorod State University, Russia \\ iskiteam@yandex.ru
}

The article analyzes the specific reasons for the occurrence of episodes demonstrating urban and rural landscapes of Lithuania and creating a distinctive atmosphere within the frame in Soviet children films. Since Vilnius baroque was influenced by Italian architecture, filmmaking in Lithuania created the illusion of Italy for Soviet cinema. Another reason lies in the ground of otherness of the culture, inside which an image of an enemy was easier to create. But along with this extreme point there is another opposite aspect in the context of Soviet children cinematograph - visual demonstration of the absolute identity of Lithuanian urban space to Russian, or, more precisely, Soviet one. The use of Lithuanian cities landscapes was mosaic by its nature. Different meaning, than the one they performed in reality, was attributed to certain places that the audience saw in frames. The urban space of Lithuania in children's Soviet cinema is devoid of its true meaning. The article reveals those patterns by which filmmakers deliberately refuse to show historical and everyday objects of this Baltic republic in a recognizable way.

Keywords: landscape contrast, Lithuania, urban environment, Soviet children's cinema, visual code.

DOI 10.23951/2312-7899-2020-1-221-231

Дия советского кинематографа Прибалтика была воплощением европейской культурной ментальности. Её природные особенности и архитектурная специфика, внутри которой происходят смешения раздичных стилей, позволяли кинематографу воссоздавать европейские реалии, не покидая замкнутого пространства советских республик. Латвия исподьзовалась для имитации визуального колорита Англии. Один из самых известных «ангдийских» проектов, снятых в Риге, который высоко был оценён самими англичанами, это фильм «Приключения Шерлока Холмса и доктора Ватсона» 
(1979-1987, режиссёр Игорь Масленников). В этом фильме в роли Бейкер-стрит выступала улица Яуниела (ил. 1). Аатвия вжилась в образ вымышленного персонажа настодько, что ежегодно в стодице отмечается день рождения известного литературного сыщика. Эстония была аналогом скандинавских стран в первую очередь по причине обидия черепичных крыш, тогда как Аитва с её барочным экстерьером/интерьером воплощала на советском экране дух Италии.

Такая визуально-кинематографическая специализация связана именно с влиянием европейских архитектурных тенденций на внешний вид городов прибалтийских республик. Однако «Собака Баскервилей» (1981, режиссёр Игорь Масленников), например, снималась как в Латвии, так и в Эстонии, в ландшафте которой много таинственных болот, где происходит ряд важных событий в произведении Артура Конан-Дойла. Хотя семантически каждая из республик Прибалтики и была «привязана» к определённой европейской стране, эти границы часто и неизбежно нарушадись.

Тематически советские фильмы, снятые в Прибалтике, связаны определённой сюжетной спецификой. Всё, что было за пределами русской обыденности, не соответствовало идеологическим представлениям о месте и времени советской действительности, выносилось за её пределы. Экранизация зарубежной литературы, например, из наиболее известных проектов - «Богач, бедняк» по роману Ирвина Шоу (1982, режиссёр Арунас Жебрюнас), «Американская трагедия» Теодора Драйзера (1981, режиссёр Марионас Гедрис) осуществлялась в Литве; там же были сняты итальянские сцены детектива по роману братьев Вайнеров «Визит к Минотавру» (1987, режиссёр Эльдор Уразбаев). Жанр детектива не имел географической привязанности к какой-дибо республике как и фильмы о разведчиках, но сериады «Семнадцать мгновений весны» (1973, режиссёр Татьяна Диознова) и «Щит и меч» (1968, режиссёр Владимир Басов) были сняты в Латвии, за которой закрепилась репутация места, где создаются кдючевые фильмы о разведывательных структурах и операциях.

Исторические фильмы также снимались в Прибалтике, на тему русской истории в том числе, особенно если герои этих фильмов отправлялись в путешествие по Европе. Например, так были сняты «Гардемарины, вперёд!» (1987, режиссёр Светлана Дружинина) и «Сказ про то, как царь Пётр арапа женил» (1976, режиссёр Александр Митта). 


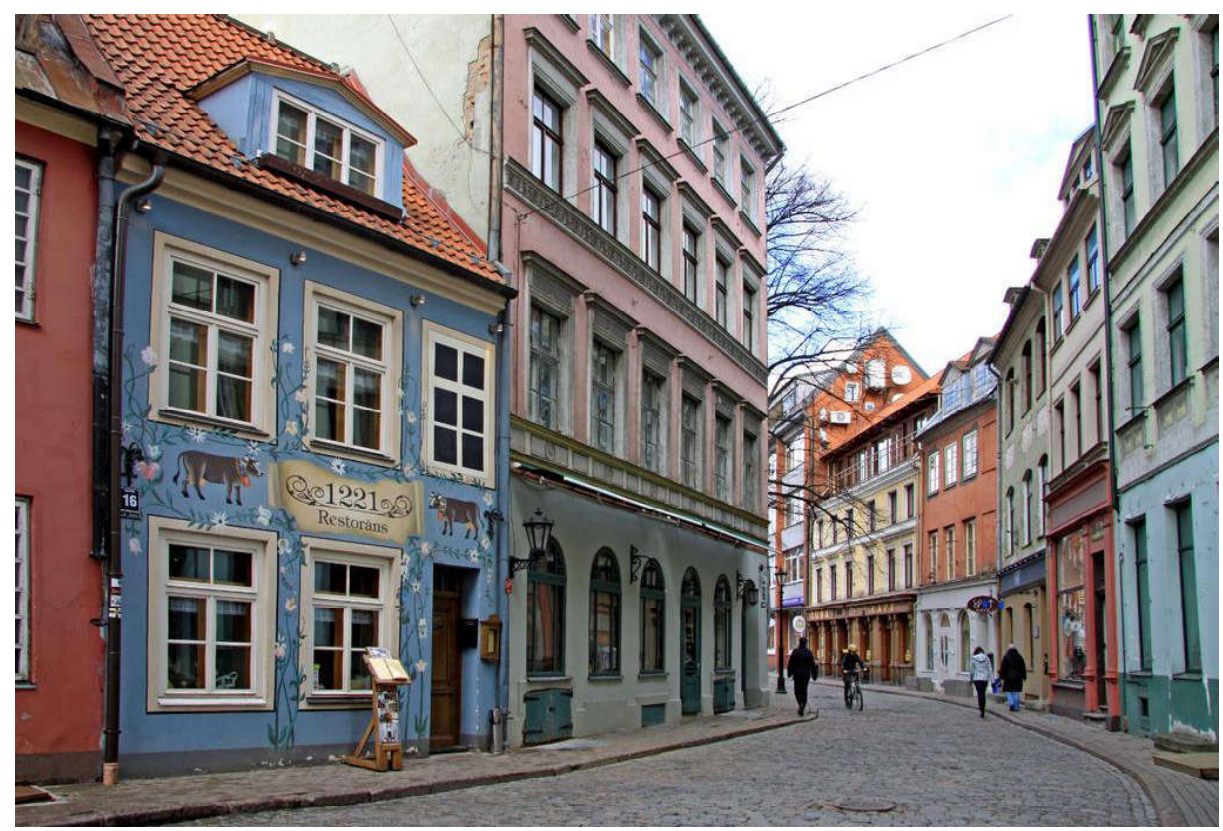

Ил. 1. Рига. Улица Яуниела

Эстония ещё в советском кинематографе брала на себя функцию Франции. В частности, известный проект “Д'Артаньян и три мушкетёра» (1979, режиссёр Георгий Юнгвальд-Хилькевич) снимался в Таллине; там же была возведена и Эйфелева башня, которая появляется в фильме «Корона российской империи, или Снова неуловимые» (1970, режиссёр Эдмонд Кеосаян). Из кудьтовых детских советских фильмов в Эстонии были сняты «Три толстяка» (1966, режиссёры Алексей Баталов, Иосиф Шапиро), «Город мастеров» (1965, режиссёр Владимир Бычков), «Снежная королева» (1966, режиссёр Геннадий Казанский), «Прикдючения жёлтого чемоданчика» (1970, режиссёр Илья Фрэз), «Малыш и Карлсон, который живёт на крыше» (1971, режиссёры Маргарита Микаэлян, Валентин Плучек), «Автомобиль, скрипка и собака Клякса» (1974, режиссёр Ролан Быков), «Проданный смех» (1981, режиссёр Леонид Нечаев). Из эстонской фактуры чаще всего в детском советском кинематографе появлялись черепичные крыши и флюгеры Талдина, а также монументальные монастырские стены.

Интересен тот факт, что советские режиссёры, снимавшие кино для детей, в качестве съёмочного подигона редко исподьзовади Датвию. Можно предположить, что данный факт связан с неким внеш- 
ним лоском, строгостью архитектурных линий, с определённой внутренней ландшафтной отстранённостью, то есть отсутствием детского начала в пространственных ориентирах названной прибалтийской республики. Исключение составляют фильмы приключенческого жанра, но они рассчитаны на разновозрастную аудиторию.

Причины обращения детского советского кинематографа к ландшафтам Дитвы раздичны и здесь включаются не тодько стилевые аспекты, но и разнообразные идеологические контексты. Чаще всего на территории Дитвы делали свои «досъёмки» определённых сцен режиссёры, работавшие на киностудии «Беларусьфильм». Факт того, что на формирование и вильнюсского барокко в частности, и литовского в целом повлияли особенности итальянского архитектурного стиля, не подлежит оспариванию; особенно это характерно для XVII-XVIII веков. «На архитектуру этого времени наибольшее влияние оказало итальянское барокко, позднее приобретшее явные региональные черты. В этот культурно-исторический период наиболее ярко проявлялся синтез искусств. Для достижения архитектурной выразительности мастерами использовались арки раздичных форм и пропорций, проёмы, их перемычки с богатыми декоративными наличниками. Обильно применялись ордерные элементы как в интерьерах, так и на главных фасадах зданий» [Климник, Орлова 2016, 75]. Эту архитектуру мы и видим в кадре.

В связи с вышесказанным представляется логичным и понятным ландшафтный визуальный ход, который использовал режиссёр Леонид Нечаев при съёмках фильма «Приключения Буратино» (1975). Что касается городских сцен, то он совмещал крымскую экзотику с тихими вильнюсскими улочками. Функционально были задействованы несколько планов. Это, во-первых, отражало всю амплитуду характера главного персонажа, во-вторых, отправляло к оригинальному литературному тексту, где всё действие происходит во Флоренции, в-третьих, придавало романтический колорит слишком безумному, динамичному, разнохарактерному пространству фильма. Например, эпизод после неслучившейся ссоры Папы Карло и Джузеппе в связи с говорящим поленом построен таким образом, что сначала зритель видит крымский пейзаж, где солнце уходит за гору, а на смену ему выходят на улицы фонарщики и зажигают фонари, исполняя песню про свет и тень. Вильнюсские улочки, высвеченные искусственным светом, воплощают и удивительное спокойствие, не соответствующее темпоритму повествования, и вместе с тем настраивают на атмосферу загадочности и таинственности. Но режиссёр сознательно вносит неожиданный 
контраст в пространство улиц литовской столицы. Фонарщики исполняют танец на улочках Вильнюса, а зажигают фонари в Крыму, что заметно по структуре стен, видимых на экране. Ландшафтный контраст часто присутствует в пространстве фильма. Школьные арочные ворота сняты в Литве, тогда как лестница, по которой спускаются Папа Карло и Буратино, чтобы отправиться в школу, имеет крымскую фактуру. Танец мойщиков улиц снят в Вильнюсе, а Буратино выбегает из литовской улицы в крымский дворик. Сцены и с фонарщиками, и с мойщиками улиц сняты в одном и том же месте Вильнюса, на одной из угловых улочек старого города.

Вторая серия фильма «Приключения Электроника» (1979, режиссёр Константин Бромберг) снята в Литве. Когда Электроника похищают и привозят в некий заграничный город, то он оказывается в руках банды Стампа (одна из лучших ролей Владимира Басова). Электроника везут в машине, из окна которой он наблюдает город. Зритель тоже смотрит на всё происходящее глазами героя и видит узкие улочки Старого города - исторический центр Вильнюса. В кадре также оказываются несколько храмов столицы Аитвы: костёл Святой Анны, костёл Святых Франциска Ассизского и Бернардина. Данный приём активирует визуальный код враждебности и принципиальной инаковости того места, в которое попал главный герой. Учитывая факт атеизма как ключевого ядра советской идеологии, можно сказать, что красота религиозных сооружений должна была вызвать у зрителя подозрения в том, что события будут развиваться в опасном для героя ключе.

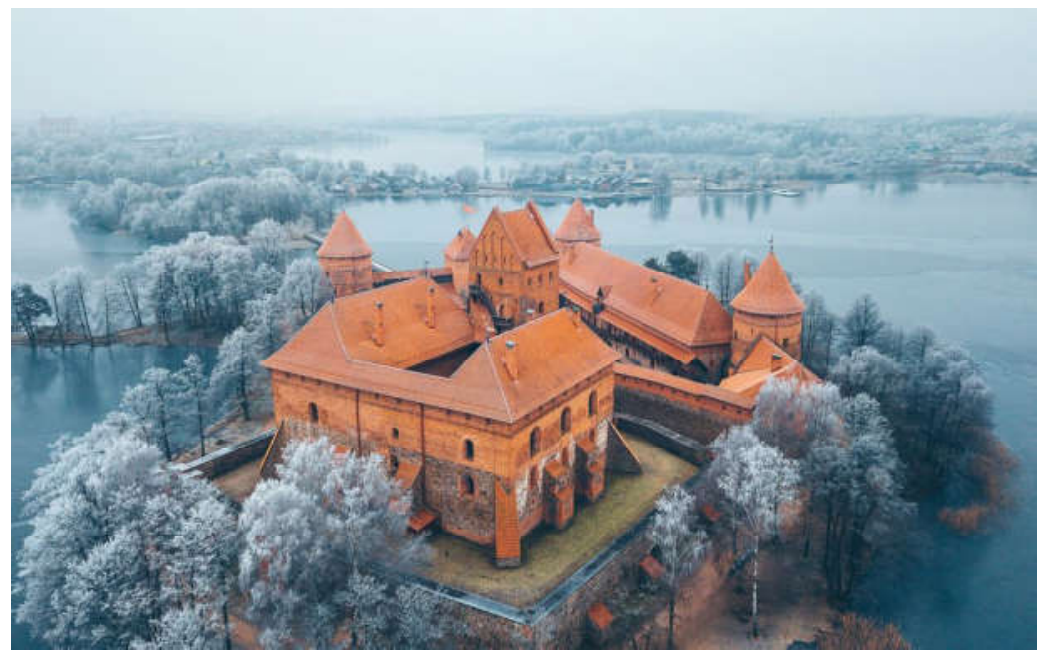

Ил. 2. Аитва. Тракайский замок 
Ключевые события «заграничной» серии разворачиваются в Тракайском замке (ил. 2). Тракай - стодица Аитвы, основанная князем Гедиминасом в 1316 году. По причине удобного местоположения ходм, окружённый водой - главный город был перенесён из Кернова в Троки (прежнее название Тракая). Сейчас в здании замка исторический музей. В фидьме бандиты утверждают, что государство не допускает простой народ к просмотру произведений искусства, а они желают восстановить справедливость. Тракайский замок состоит из нескольких зданий, связанных между собой. Он представляет городище с закрывающимися воротами и пдощадыю в центре. В правом дальнем углу площади есть башня; именно ворота, ведущие внутрь неё, и «сыграли» в фильме «роль» музейных ворот. Помещение, в котором происходит сцена ограбления, - это тёмная сводчатая зала, на её стенах не висят картины - как в реальности, так и в фильме. По сути, авторам необходим был антураж, который визуально приближал бы зрителя к ощущению того, что всё происходит в какой-то другой, европейской, сумрачной стране. Контекст использования Тракайского замка связан также с возможностью визуально погрузиться в эпоху Средневековья.

Дитва в качестве фактуры была использована в названном фильме ещё и с другой целью. Несколько сцен были сняты в районе Даздинай (ил. 3). Таким образом, в фильме появляется другой Вильнюс. В первую очередь это современная, огромная, необычная по меркам советской действительности школа, где происходят основные события большей части фильма.

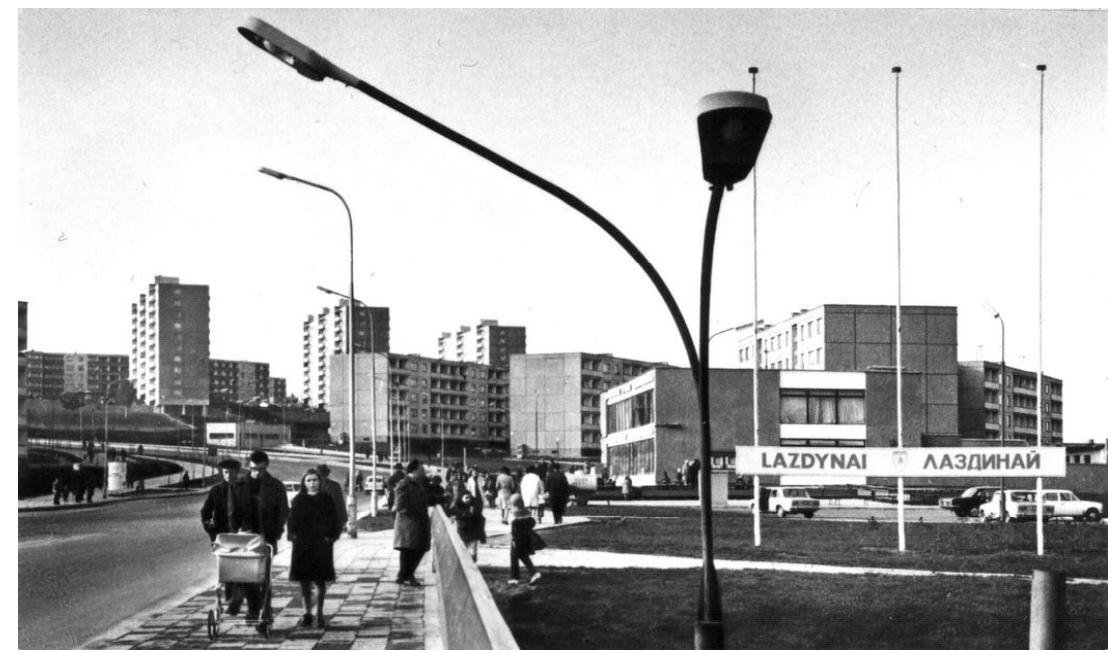

Ил. 3. Вильнюс, район Лаздинай 
В «Приключениях Электроника» ландшафты Аитвы появляются для усиления контрастности. С одной стороны, создание образа врага через разнокалиберную банду Стампа и погружение в атмосферу иной культуры с налётом Средневековья. С другой стороны, предпринимается попытка приукрасить советскую действительность. Основные съёмки происходиди в Одессе. Город представлен в фильме так, что зритель должен поверить в то, что все города Советского Союза выгдядят подобным образом. Уникальная школа с огромными кабинетами, красивыми лестницами и стекдянными стенами тоже должна была восприниматься как нечто привычное и обыденное для советской действительности.

Антропологический дискурс Аитвы в данном фильме наполнен дискретностью и смысдовой подярностью. Городское пространство дишено присущей ему семантики, оно мозаично и обрывисто. Более того, повторяются определённые ракурсы улиц и зданий, отсутствует перспектива, внутри которой отражался бы образ Вильнюса или Тракая. Авторы фильма намеренно лишают объекты узнаваемости, наделяя их совершенно иным функционалом. Оба города совмещены в некоем условном фантасмагорическом пространственном иокусе. В фильме «Приключения Электроника» Дитва исподьзована с единственной целью - она воплощает собой «загнивающий» Запад, где отсутствуют морадьные ценности. На таком визуальном материале легко создать образ врага.

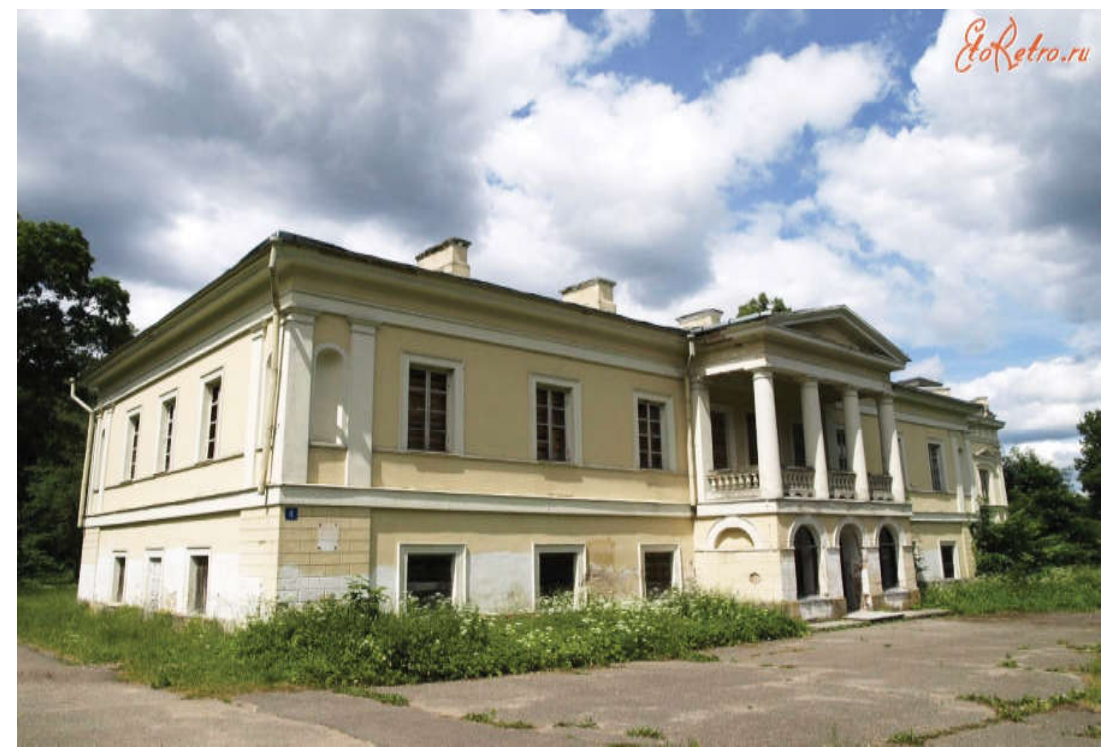

Ил. 4. Яитва. Яшюнай 
В Вильнюсском районе Лаздинай был снят внешний вид школы и школьный двор, где в фильме и происходят основные «детские» конфликты. Если выявлять мотивы обращения к данному месту, то можно предположить, что в этом случае целеполагание то же, что и в фильме «Чудак из 5 Б» (1972, режиссёр Илья Фрэз). Здесь герои постоянно бродят по городу, который визуадьно выгдядит привычно и обыденно. Город показан без перспективы в глубину. Он как будто ничем не отличается от среднестатистического советского населённого пункта. Нужно пристально вглядываться, чтобы внутри кадра узнать районы и улицы Вильнюса. В фильме представлен как старый город, так и новые районы столицы Аитвы. Есть абсолютно узнаваемые пространственные элементы, из которых складывается Вильнюс: набережная реки Нярис, которая делит город на две части - современную и историческую; магазин, где герой ищет подарок для матери, - это начало старого города, улочки и здания которого тоже с разной периодичностью мелькают на экране. Город намеренно снят таким образом, чтобы он не был идентифицирован как столица Иитвы. Семантически ставится знак равенства между городским пространством прибалтийской республики и дюбым населённым пунктом в Советском Союзе.

И последний детский советский фильм, который необходимо поставить в один ряд с предыдущими, - это «Бронзовая птица» (1974, режиссёр Николай Калинин). Он был снят в усадьбе Яшюнай, расподоженной недалеко от Вильнюса (ил. 4). Здание, построенное в стиле ампир с элементами романтизма, явдяется родовым имением Балинских. Один из представителей этого рода, Иван Балинский, является основателем российской психиатрической школы. Усадьбу эту посещал даже ведикий поэт Адам Мицкевич, и для своего времени она стала культурным центром. Само место, где она расположена, включает красивые и вместе с тем несколько таинственные пейзажи. Открытое пространство чередуется с зарослями, где прячутся болота; и посреди всего этого природного великолепия высится усадьба. Яшюнай оказывается идеадьным местом ддя съёмок фильма «Бронзовая птица». Стилистически этот детский фильм снят по «нуаровским» принципам с доминированием атмосферы неопределённости и таинственности, где герои только кажутся носителями заявленных качеств, но не явдяются таковыми на самом деле. Идеальным примером такого несоответствия в фильме становится «Графиня», каковой её считают мальчишки; на самом деле она всегда была в этом столь притягательном для пионеров доме служанкой. Дети ищут врага, и они его находят, идя по его 
следу, иногда слишком увлекаясь. В контексте данного сюжета ландшафт маленького дитовского города оказывается удобным для воссоздания атмосферы неопределённости, таинственности, а усадьба как бы враждебна сама по себе, уже одним своим видом. Она по сути уже враг. Дом условно персонифицирует враждебный образ даже без явного присутствия в нём чедовека и на этом основании отвергается новой идеологией.

Такая идеология, по словам Е. Артемьевой, «провоцирует детейкиногероев на аномальные, совершенно недетские поступки. Объяснить эту несогласованность можно не через вечную проблему “отцов и детей”, а через разграничение двух понятий - ума и мудрости. Умом в самом положительном смысле отныне наделяются исключительно дети и подростки, мудрость с отрицательными коннотациями (она - из прошлого) отдаётся взросдым» [Артемьева 2013, 155].

Итак, литовский ландшафт в советском детском кинематографе появлялся по нескольким причинам:

1. Удицы Вильнюса создают илдюзию Италии, то есть городской ландшафт как будто аутентичен природе самого героя («Приключение Буратино»);

2. Это инаковое, чужое пространство, где легко найти врага и воплотить его в реальность. Он может быть нелепым и современным (Стамп, «Приключения Электроника») или коварным и изысканным (Граф, «Бронзовая птица»);

3. Исподьзуется визуадизация городского пространства Дитвы как естественного и привычного для дюбого советского города.

В заключение скажем, что литовские режиссёры в советский период часто обращадись к детскому кинематографу. Первый детский фильм, снятый в Аитве, - «Голубой горизонт» (1957, режиссёр Витаутас Микалаускас). Он наиболее показателен в плане использования ландшафтных съёмок. Мальчишки бегут к морю. Зритель видит хутора, лес, заброшенные дороги и водоёмы; и почти полностью отсутствует городская фактура. В детском дитовском кинематографе пространство было либо предельно условным (некая вымышленная страна, ситуация, не имеющий аналогов с реальностью антураж), либо действие фильма происходило в деревне, у моря, в лесу. Город появдялся только в экранизациях произведений зарубежных авторов. Но это уже другая тема, требующая отдельного исследования. 


\section{БИБЛИОГРАФИЯ}

Артемьева 2013 - Артемьева Е. Детские и подростковые образы в советском кинематографе: культ юности и страх перед ней // Вестник Московского университета. Серия 9: Филология. 2013. № 3. C. 154-159.

Епишин, Хохлова 2017 - Епишин А., Хохлова М. Стидистические особенности национального романтизма в архитектуре стран Прибалтики // Sciences of Europe. 2017. № 15-1 (15). С. 3-6.

Каплунайте 2011 - Каплунайте И. Дома-башни в г. Вильнюсе в XIVXV вв. // Археология и история Пскова и Псковской земли. 2011. № 26 (56). C. 178-182.

Килимник, Орлова 2016 - Килимник Е., Орлова Ж. Памятники барокко и кдассицизма в Дитве XVIII-XIX вв. // Теория и практика мировой науки. 2016. № 3. С. 75-77.

Сурдокайте 2011 - Сурдокайте Г. О традиции одевания скульптур в Дитве в XVII-XX вв. // Дом Бурганова. Пространство культуры. 2011. № 4. C. 123-143.

Материал поступил в редакциию 15.09.2019 